\title{
Cervical Disc Herniation Presenting with Chest Wall Pain
}

\author{
Michael C. Yeung and Neil A. Hagen
}

\begin{abstract}
This report highlights the clinical features of two patients who presented with severe neuropathic chest wall pain caused by herniated C6-7 disc, and speculates on the pathophysiology of this syndrome. Worsening of symptoms with neck movement helped localize the process as cervical spine rather than plexus in origin. Both patients had herniated C6-7 disc material compressing the spinal cord and C7 nerve root, and neurological symptoms resolved promptly following surgery. Neuropathic chest wall pain should alert the clinician to consider the diagnosis of cervical disc herniation and prompt definitive imaging of the cervical spine by myelography or magnetic resonance imaging (MRI).

RÉSUMÉ: Hernie discale à C6-7 avec comme symptôme initial une douleur à la cage thoracique. Ce compte rendu souligne les manifestations cliniques chez deux patients qui se sont presentés avec des douleurs neuropathiques sévères à la cage thoracique causées par une hernie discale à C6-7 et discute de la pathophysiologie de ce syndrome. Une exacerbation des symptômes à la mobilisation du cou a aidé à localiser l'origine de la douleur à la colonne cervicale plutôt qu'au plexus. Les deux patients avaient une compression herniaire à C6-7 comprimant la moelle épinière et la racine nerveuse $\mathrm{C}$, et les symptômes neurologiques sont disparus rapidement après la chirurgie. En présence d'une douleur neuropathique à la cage thoracique le clinicien devrait considérer le diagnostic de nernie discale cervicale et recourir à la myélographie ou à l'imagerie par resonance magnétique (MRI).
\end{abstract}

Can.J. Neurol. Sci. 1993; 20:59-61

Herniation of a cervical intervertebral disc can occasionally be associated with a minor degree of chest wall discomfort. However, chest wall pain as the major presenting complaint of herniated cervical disc is unusual. In this report, we present 2 such cases, both of which were referred to a neurologist as "possible brachial plexopathy."

\section{Case Report}

Patient 1: A 40-year-old woman felt a "pop" in her right shoulder while getting into her dressing gown. Subsequently, she developed severe right shoulder, arm, and hand pain which persisted as a constant achiness. This was associated with symptoms of dysesthesia and hyperpathia. The pain was greatest in a $\mathrm{C} 7$ and $\mathrm{C} 8$ distribution but also involved the anterior and posterior chest wall to about the T6 level. Ten days after onset of her symptoms, she presented to the emergency room and was subsequently referred to a neurologist with the diagnosis of "possible brachial plexopathy."

Physical examination revealed mild weakness of the right triceps, supinator, and wrist extensor muscles; biceps reflexes were less brisk on the right than the left. There was no evidence of myelopathy. Sensory examination demonstrated hypesthesia, hyperpathia and cutaneous allodynia in a right C5 - T6 distribution, to about the midline posteriorly and anteriorly (Figure 1). Neck extension, flexion, Spurling's manoeuvre, and coughing made the right arm symptoms markedly worse. Clinical diagnosis was of an extruded disc at the C6-7 level.
Cervical spine $X$-rays showed minimal degenerative disc disease changes with mild reversal of the normal cervical lordosis. Myelography and postmyelogram computerized tomography (CT) imaging revealed a large right $\mathrm{C} 6-7$ posterolateral disc herniation with inferior and superior extrusion of disc material, and effacement of the spinal cord (Figure 2).

An anterior C6-7 discectomy and spinal fusion was performed. At operation, a large fragment of disc material was removed. Postoperatively, there was prompt improvement of her symptoms and signs.

Patient 2: A 48-year-old woman developed gradual onset of achiness over the right posterior shoulder area which increased in severity and distribution over 2 days. The pain was described as "excruciating" and "a deep ache". Pain would also come in trains of lancinating episodes in the same distribution, with jabs occurring every 15 seconds. Pain eventually involved the neck, right shoulder, arm, forearm, and hand, especially the lateral 3 digits. She also described an achy sensation across the right chest wall extending to the nipple line and into the axilla. There was mild tingling of digits 4 and 5 on the right, and a complaint of a weak hand grip.

Physical examination revealed slight weakness of the right wrist flexors, finger flexors, and the flexor pollicus longus. Reflexes were present and symmetrical. Light touch in the right chest wall in a T2 - T6 distribution resulted in a "deep ache" sensation in the right elbow. The sensory examination was otherwise normal. Neck extension or flexion produced episodes of sharp, shooting, lancinating pain radiating down the right arm. The clinical diagnosis was brachial plexitis or a cervical intracanalicular process.

From the Department of Clinical Neurosciences, Foothills Hospital (M.C.Y., N.A.H.) and Faculty of Medicine, University of Calgary (N.A.H.) Received May 25, 1992. Accepted in final form October 5, 1992

Reprint requests to: Neil A. Hagen, M.D., Department of Clinical Neurosciences, Foothills Hospital, 1403 - 29th Street N.W., Calgary, Alberta, Canada T2N 2T9 
She was started on carbamazepine pending workup; the sharp shooting lancinating arm pain became much less severe.

Myelography and postmyelogram CT imaging revealed a right posterolateral disc protrusion at the C6-7 level with deviation of the cord and dural sac anteriorly and to the left (Figure 2). Nerve conduction studies including $F$ waves were within normal limits. Electromyography performed 21 days into the illness showed only evidence of mild chronic denervation in low cervical paraspinal muscles consistent with a $\mathrm{C} 7$ radiculopathy.

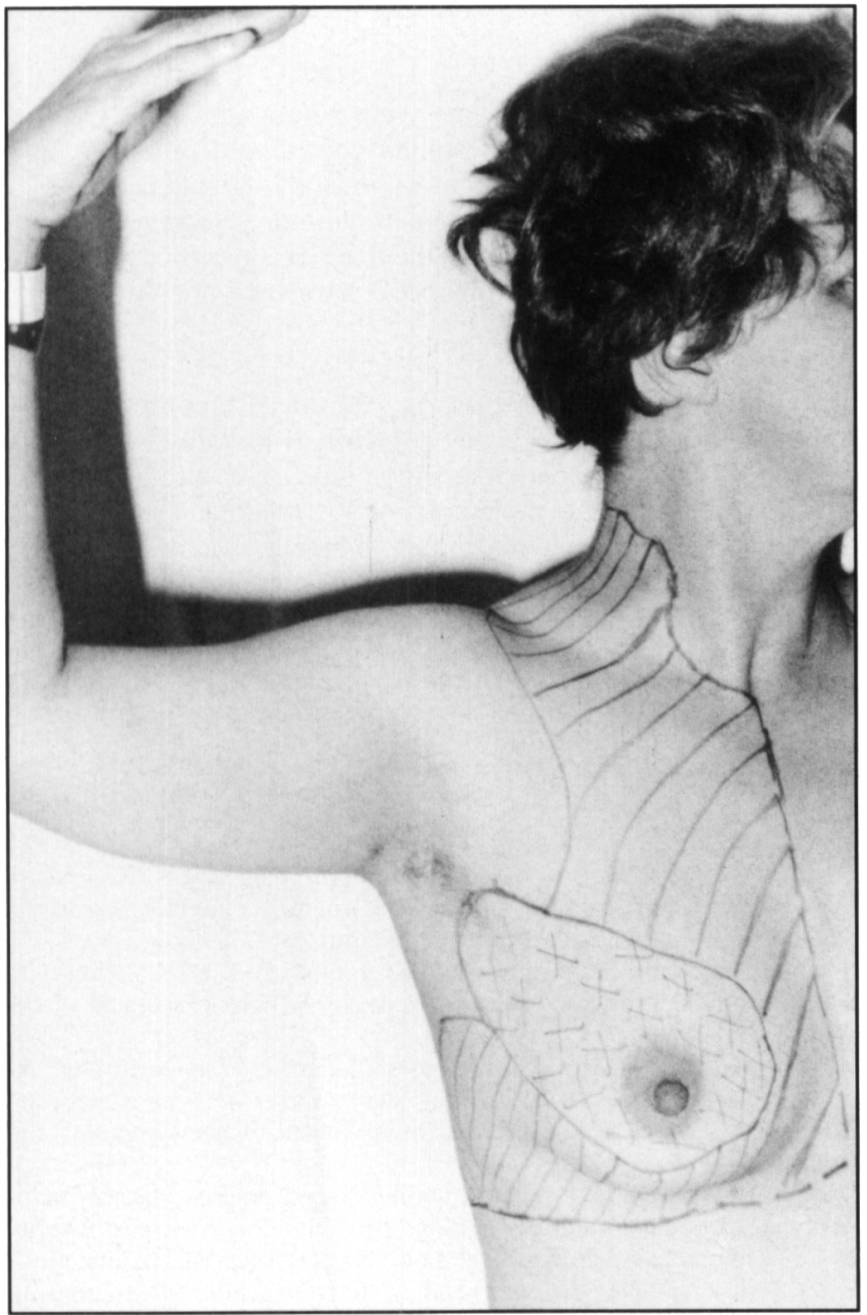

Figure 1 - Sensory examination of patient 1: striped area represents minimal hypesthesia; cross-hatched area represents mild hypesthesia with hyperpathia; unmarked area (shoulder, arm. and hand) represents moderate hypesthesia.
An anterior C6-7 discectomy and spinal fusion was performed. At operation, a large fragment of extruded disc material was removed with good decompression of the intervertebral foramen.

Postoperatively, there was prompt improvement of her symptoms.

\section{DISCUSSION}

Chest wall pain ipsilateral to herniated cervical disc is uncommon but well described; in a personal series of 648 patients, Murphey et al. noted the complaint "occasionally" in each of $\mathrm{C} 5, \mathrm{C} 6, \mathrm{C} 7, \mathrm{C} 8$ and $\mathrm{T} 1$ radiculopathies. ${ }^{1}$ Nachlas described the phenomenon as "pseudoangina pectoris" in $1934 .^{2}$ Case 6 described by Michelsen had neuropathic chest wall pain and cervical radiculopathy; both were immediately relieved by resection of a disc fragment compressing the ipsilateral $\mathrm{C7}$ nerve root. ${ }^{3}$ Other patients with $\mathrm{C} 6-7$ disc rupture have been described to have chest wall pain mimicking coronary artery disease. ${ }^{4.5}$ However, this clinical picture is unusual; in a careful study of 100 consecutive patients with neurologic involvement from cervical disc protrusion, no patient was described with chest wall pain. ${ }^{6}$

Speculation as to the pathophysiology of this referred pain was concentrated on the anatomic structure of the cervicothoracic spine and the brachial plexus. A myotomal rather than dermatomal distribution of arm and chest wall pain has been felt by some authorities to be evidence of a myotomal origin of this chest wall pain. ${ }^{3}$ In the two patients who are the subjects of this report, compression of the $\mathrm{C} 7$ nerve root by disc material. was only moderate, as seen radiographically and at surgery. Effacement of the spinal cord, however, was prominent. We speculate that neuropathic chest wall complaints may be spinal cord in origin, either due to compression of the ipsilateral tract of Lissauer, or to traction of the cervical nerve root at the spinal cord level.

\section{Conclusion}

Neuropathic chest wall pain can be seen in C6-7 disc herniation, although its pathophysiology remains uncertain. Neuropathic chest wall pain should alert the clinician to consider the diagnosis of cervical disc herniation and prompt definitive imaging of the cervical spine by myelography or MRI.

\section{REFERENCES}

1. Murphey F, Simmons JCH, Brunson B. Ruptured cervical discs, 1939 to 1972. Clin Neurosurg 1973; 20: 9-17.

2. Nachlas IW. Pseudo-angina pectoris originating in the cervical spine. JAMA 1934; 103: 323-325.

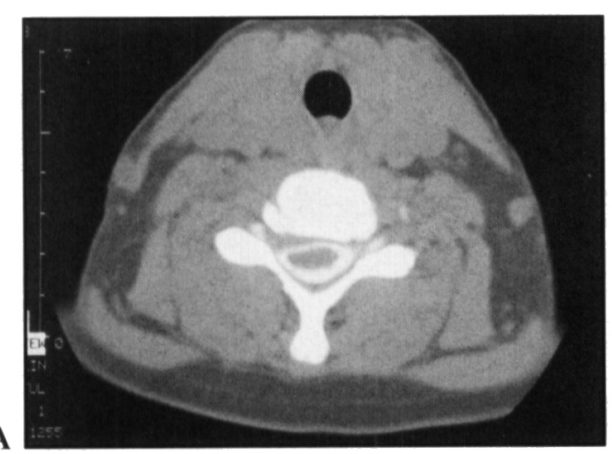

B

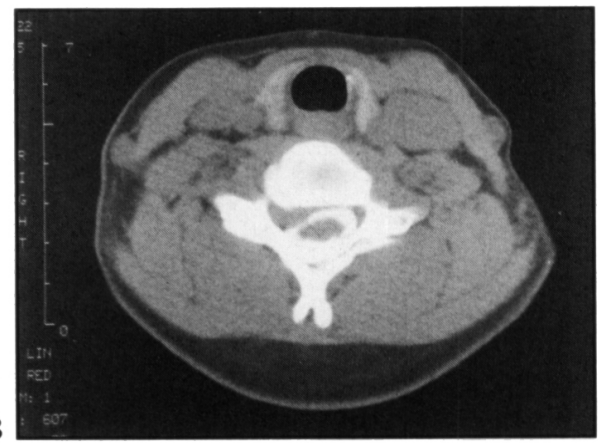

Figure 2 - Postmyelographic CT at C6-C7 interspace from patients 1 (left) and 2 (right), showing compression of the right side of the cervical spinal cord by a large herniated disc. 
3. Michelsen JJ, Mixter WJ. Pain and disability of shoulder and arm due to herniation of the nucleus pulposus of cervical intervertebral disks. N Engl J Med 1944; 231: 279-287.

4. Hanflig S. Pain in the shoulder girdle, arm and precordium due to cervical arthritis. JAMA 1936; 106: 523-526.
5. Semmes RE, Murphey F. The syndrome of unilateral rupture of the sixth cervical intervertebral disk. JAMA 1943; 121: 1209-1214.

6. Yoss RE, Corbin KB, MacCarty CS, et al. Significance of symptoms and signs in localization of involved root in cervical disk protrusion. Neurology 1957; 7: 673-683. 